\title{
Recent advances in cardiovascular aspects of polycystic ovary syndrome
}

T Sathyapalan and S L Atkin

Hull York Medical School, Academic Endocrinology, Diabetes and Metabolism, Michael White Diabetes Centre, 220-236, Anlaby Road, Hull HU3 2RW, UK

(Correspondence should be addressed to T Sathyapalan; Email: thozhukat.sathyapalan@hyms.ac.uk)

\begin{abstract}
Polycystic ovary syndrome (PCOS) has been associated with increased cardiovascular risk (CVR) markers, but population studies have not clarified whether there is an increase in cardiovascular morbidity and mortality. Four different PCOS phenotypes resulted from the Rotterdam criteria that may differ in their CVR potential, thus introducing further complexity. This has led to studies using surrogate CVR markers including biomarkers in blood and imaging such as flow-mediated vasodilatation. In PCOS, both peripheral and central insulin resistance (IR) have been shown. Weight loss has been shown to improve IR and visceral fat, while insulin sensitizer therapies with metformin or thiazolidinediones improve IR and endothelial dysfunction. IR is also found in non-alcoholic fatty liver disease that in turn is very common in PCOS; studies have suggested that IR may be improved by treatment with metformin and omega-3 fish oils. PCOS patients have a more dyslipidemic phenotype that is worse in 'classical PCOS' associated with a higher CVR. Studies with atorvastatin and simvastatin have reported a decrease in the lipid parameters and an improvement in CVR indices including IR, but it is unclear whether this is due to their lipid-lowering action or a pleiotropic effect of the statin. In this expert opinion review, the relevant literature published during the last 2 years was considered. It focuses on some recent important data that has emerged while also exposing the gaps that remain in our knowledge that need to be addressed.
\end{abstract}

European Journal of Endocrinology 166 575-583

\section{Background}

In Greek mythology, cutting off the head of the Hydra led to the re-growth of several more heads from the stump. This is akin to the replacement of the National Institute of Health (NIH) workshop criteria for the diagnosis of polycystic ovary syndrome (PCOS) by the Rotterdam consensus criteria (1) that has led to four PCOS phenotypes: 'classical' oligomenorrhea, hyperandrogenism, and polycystic ovaries; oligomenorrhea and hyperandrogenism; oligomenorrhea and polycystic ovaries; and hyperandrogenism and polycystic ovaries without menstrual irregularity. This resulted in the need to define whether each of the phenotypes was equal in terms of cardiovascular risk (CVR), metabolic aspects, and reproductive issues. The first study reported the prevalence of PCOS in women of reproductive age in a Greek population to be around $7 \%$. The current accepted prevalence of $6-10 \%$ for PCOS was based on studies applying the NIH criteria but has been estimated to have increased to $20 \%$ using the Rotterdam criteria (2), in turn increasing the potential
CVR to a much greater number of premenopausal women. Further, subclassification based on obese or non-obese PCOS has led to a confusion of greater potential and a large increase in the literature. This is partially addressed by the Androgen Excess and PCOS (AE-PCOS) Society criteria for PCOS suggesting that PCOS should be defined by the presence of hyperandrogenism (clinical and/or biochemical), ovarian dysfunction (oligo-anovulation and/or polycystic ovaries), and the exclusion of related disorders (3). A critical review of recent clinical and scientific advances is necessary to direct current best clinical practice and to determine the direction for focus on future scientific research. This narrative review attempts to address these issues by giving an overview of the literature focusing on advances since 2009.

\section{Population studies}

Contradictory results from observational population studies make it difficult to assess the potential for PCOS 
to enhance cardiovascular morbidity and mortality. Initial studies on patients with PCOS undergoing wedge resection suggested that there was no increase in cardiovascular mortality (CVM) (2). Conversely, the Nurses' Health Study has shown that women with a history of menstrual irregularity have an increased risk of both non-fatal and fatal coronary heart disease (CHD) (4).

As testosterone levels tend to fall after menopause, the elevated levels here may identify a more at-risk group. Recent data have not helped to clarify the situation. A relationship between menstrual irregularity and an increase in the age-adjusted risk for CVM was recently reported (5), though this was not significant when body mass index (BMI) was adjusted for in this cohort.

Studies on postmenopausal, middle-aged, and elderly women have shown that there was a significantly increased age-adjusted risk for incident CHD and events for the highest quintiles of total, bioavailable, and free testosterone relative to the median and bottom quintiles $(6,7)$. Although these studies did not distinguish between women with a history of irregular menses or PCOS, the above data have implications for the cardiometabolic role of hyperandrogenemia, which persists after menopause in PCOS women (8).

Thus, the evidence supports the need for a prospective long-term adequately powered observational trial to determine whether PCOS patients are at a sufficiently increased risk of cardiovascular events to warrant a more decisive intervention as is seen for patients with type 2 diabetes.

\section{PCOS phenotypes}

The use of Rotterdam consensus criteria (1) has led to four PCOS phenotypes: 'classical' oligomenorrhea, hyperandrogenism, and polycystic ovaries; oligomenorrhea and hyperandrogenism; oligomenorrhea and polycystic ovaries; and hyperandrogenism and polycystic ovaries without menstrual irregularity. Of the four phenotypes possible within the spectrum of PCOS based on the Rotterdam criteria, the phenotype without hyperandrogenism (only oligomenorrhea and polycystic ovaries) has been controversial (9). The classical phenotype of oligomenorrhea, hyperandrogenism, and polycystic ovaries in comparison with the other subtypes has higher BMI due to greater general and central obesity, more severe insulin resistance (IR) and a higher prevalence of dyslipidemia and other CVR markers $(2,9,10,11)$. According to the AE-PCOS Society consensus statement (12), ovulatory PCOS patients have a lower BMI, lesser degrees of hyperandrogenism and hyperinsulinemia, reduced metabolic syndrome prevalence, and milder forms of dyslipidemia whereas non-hyperandrogenic PCOS patients have the most metabolically favorable profile, often indistinguishable from normal women. While those with ovulatory
PCOS appear to have less instances of increased CVR, it is still greater than in normal controls $(9,10,11)$. In a recent systematic review and meta-analysis, there was a twofold risk of arterial disease for patients with PCOS relative to women without PCOS (13). This twofold risk estimation of arterial disease was based on five studies, and this finding was robust when the two BMI-matched studies were pooled (13).

However, what is striking is that the 'non-classical' PCOS phenotypes generally have lower BMI, which raises the question as to whether they would be classified as being 'classical' if they were to be weight matched with a BMI $>30$. In this regard, the differing phenotypes could simply be part of a continuum whose clinical manifestations are expressed with increasing body weight. In an observational study, it was shown that the more insulin-resistant phenotypes were also the most hyperandrogenemic and were the most prevalent phenotypes (14).

\section{Surrogate CVR markers}

\section{CVR markers in blood}

Owing to the lack of outcome studies to determine whether PCOS is associated with increased morbidity and mortality, a wealth of surrogate markers have been reported. A wide (and bewildering) variety of additional CVR markers have been proposed.

In a meta-analysis looking into the relationship between PCOS and CVD, various CVD risk markers were analyzed (15). A total of 130 data sets in 11 different outcomes, involving 7174 and 5076 CVD markers in women with PCOS and controls respectively, were taken into account. It was found that women with PCOS showed significantly elevated CRP, homocysteine, plasminogen activator inhibitor-1 (PAI-1), PAI-1 activity, vascular endothelial growth factor, asymmetric dimethylarginine (ADMA), advanced glycation end products (AGEs), and lipoprotein a (Lp(a)) concentrations compared with controls, yet with significant between-study heterogeneity (15). Whether this apparent increase in risk is translated into CVD later in life needs to be elucidated.

Increased serum AGEs have been shown to be a distinct finding in PCOS women, independent of obesity and IR (16). It has been shown that in postmenopausal women, higher levels of AGEs were positively associated with higher androgen levels (17). This association was suggested to be a potential pathophysiological mechanism contributing to the described higher prevalence of cardiovascular events in postmenopausal women with higher androgen levels (with and without PCOS features).

Endothelin-1, a marker of abnormal vascular reactivity, seemed to be increased in the obese and non-obese women with PCOS compared with the agematched controls, independently of the presence of 
obesity (18). A positive correlation of endothelin-1 with free testosterone levels as well as a negative correlation of endothelin-1 with glucose utilization in the total studied population was also shown (18).

Elevated interleukin 18 (IL18) has been associated with CVR, and in a study of 60 PCOS patients, IL18 was elevated in PCOS and correlated with IR; however, the elevation appeared to be accounted for by obesity rather than PCOS as an independent factor (19). Plasma advanced oxidation protein products are associated with oxidant-mediated protein damage that was shown to be higher in PCOS and was independently related to IR. It was associated with higher oxidative stress measures and elevated highly sensitive C-reactive protein (hs-CRP) while being unrelated to obesity (20); this may be a useful marker in studies with both obese and non-obese PCOS subjects. Others looked at ischemia-modified albumin (IMA) that reflects chronic hypoxia and oxidative stress, which was found to be elevated in PCOS. However, only hs-CRP correlated with IMA suggesting that its elevation was a marker of increased oxidative stress perhaps due to the chronic inflammation found in PCOS (21). Urinary albumin excretion (UAE) affects endothelial dysfunction and in diabetes correlates with CVD. It was surprising to see UAE at overt microalbuminuria levels reported in $24 \%$ of normotensive, non-diabetic women with PCOS as this is a higher prevalence than that seen in diabetic patients. The UAE correlated with diastolic blood pressure, insulin, 17-hydroxyprogesterone, and prolactin in these patients (22). Should these findings be confirmed and the mechanism identified, this could have important clinical implications in guiding whether anti-hypertensive therapy should be implemented as it is for diabetes.

In another study on women with PCOS as per NIH and Rotterdam consensus definitions, ADMA, which is an inhibitor of nitric oxide (NO) synthase and serves as a CVR marker, was highly compared with controls independent of age and adiposity (23). However, no differences in other markers of endothelial function or arterial stiffness were apparent between phenotypes in this PCOS cohort (23).

Platelet function is directly related to endothelial health, and early studies have been performed in non-obese insulin-resistant PCOS patients showing increased platelet aggregation (24). However, recent data suggested that platelet aggregation is increased and its inhibition using the NO donor sodium nitroprusside is impaired in both lean and overweight PCOS patients compared with controls, but the magnitude of the abnormalities did not correlate with IR, BMI, or androgen levels (25).

Clinically, the lipid accumulation product index that combines waist circumference and the triglyceride concentration was shown to correlate with IR. Receiver-operating curve analysis showed the lipid accumulation product index to have better performance than non-HDL-cholesterol or BMI in identifying IR (26); this may have some usefulness in clinical practice.

\section{CVR markers by imaging}

Endothelial cell dysfunction is recognized as one of the earliest markers of CVD, but reports of its occurrence in PCOS have been conflicting $(27,28)$. Imaging studies have added weight to the suggestion that endothelial damage occurs early in young women affected by PCOS $(29,30)$. The studies have included: angiography, suggesting that PCOS women have more extensive coronary disease; increased carotid intimal thickness on ultrasound; and increased coronary artery wall calcium determined by electron beam computed tomography (EBCT), another non-invasive measure that reflects coronary artery disease. Using EBCT and aortic magnetic resonance imaging (MRI) for aortic plaque, there were no differences in PCOS subjects despite the higher BMI of that population (31), though whether this may be due to the population under study or sensitivities of detection are unclear. Studies have suggested that blood vessels are more inelastic in PCOS.

It was shown by brachial artery flow-mediated dilation (FMD) that the blood vessels are more inelastic and impaired in PCOS patients, independent of obesity $(29,30,32,33)$. This again suggests that peripheral vascular distensibility reflects both obesity and PCOS (perhaps through IR) as independent variables. However, in a recent pilot study, it has been shown that FMD in both normal weight and overweight PCOS subjects was attenuated to the same degree in overweight subjects without PCOS (34), but the sample size was small in this study.

Further evidence on the potential independent effect of PCOS on endothelial function was seen in a study on the daughters of women with PCOS who had a normal BMI, were eumenorrheic but had polycystic ovaries on ultrasound. These subjects showed increased IR and decreased brachial response to FMD compared with controls (35). Whether arterial stiffness is a factor in CVR has been approached by others in a different manner: aortic stiffness and distensibility has been shown to be an accurate measure for coronary artery disease; however, these measures were not shown to be increased in a study of non-obese PCOS patients, suggesting that PCOS is not associated with CVR (36). Confirmation that central obesity rather than PCOS per se increased arterial stiffness substantiates this (37). Concordant findings have been reported by another study that showed that women with PCOS who are young, non-obese and have no biochemical evidence of IR, have abnormal vascular function but normal arterial stiffness when compared with age- and weight-matched control subjects (38).

It has been shown that autonomic innervation of the heart may be affected in PCOS with increased sympathetic and decreased parasympathetic 
components of heart rate variability (39). In a recent study of 75 women with PCOS and matched controls heart rate recovery, a measure of autonomic dysfunction associated with increased mortality was impaired in PCOS after maximal cardiopulmonary exercise testing, and was inversely related to BMI (40). The authors showed that there was also a reduced $\mathrm{VO}_{2}$ max indicating cardiopulmonary impairment, but additional autonomic function studies are required to confirm this. However, obstructive sleep apnea (OSA) was not excluded and this may be important in this finding. OSA is a common finding in PCOS and an independent risk factor for CVD (41). In a study of 56 PCOS patients, of whom 26 met the inclusion criteria for OSA, following 8 weeks of continuous positive airway pressure (CPAP), there was a modest $(7 \%)$ reduction in insulin sensitivity with the suggestion that the effect was attenuated by obesity and enhanced with longer CPAP therapy (42). Most striking was the improvement in heart rate variability (a measure of cardiac autonomic function with lower sympathetic and higher parasympathetic tone) by $44 \%$ after CPAP; norepinephrine and daytime diastolic blood pressure were also decreased (42). While this was a small study that was not placebo controlled, it may in part explain the findings of altered cardiac autonomic function, but further studies need to confirm this.

Overall, these surrogate marker studies give enhanced tools to be employed in the investigation of CVR, but their utility needs to be determined by their combination, PCOS phenotype, control selection and larger population studies.

\section{Metabolic syndrome and PCOS}

With the high prevalence of obesity, increased IR, hypertension, and dyslipidemia, it is not unexpected that metabolic syndrome affects $33-47 \%$ of patients with PCOS. The prevalence of metabolic syndrome in subjects with PCOS is up to twofold higher than in weight-matched subjects, with an increased prevalence as obesity increases (2). Metabolic syndrome is three times more common in classical PCOS than in other subtypes (10). In a recent study looking into phenotype and metabolic profile of South Asian women with PCOS, young indigenous South Asians with PCOS have greater odds of being centrally obese compared with BMImatched controls, with a third having metabolic syndrome that bears no relationship with the androgenic phenotype. The significant predictors for metabolic syndrome within the PCOS cohort were advancing age, obesity determined by the Asian cut off (BMI $>25 \mathrm{~kg} / \mathrm{m}^{2}$ ), and acanthosis nigricans, while family history of diabetes, hyperandrogenism, and elevated SHBG did not have any predictive value (43), suggesting that we also have to factor ethnicity into equation. However, whether metabolic syndrome confers a CVR over and above the sum of its parts is still unclear. This does suggest that future studies need to pay particular attention to the careful selection of PCOS phenotypes and control subjects in CVR studies to ensure that unambiguous data are collected and interpreted.

\section{IR and PCOS}

Although the diagnosis of PCOS is not a part of the criteria, IR is common in $60-80 \%$ of PCOS subjects and thought to be a major independent component of CVR $(44,45)$. However, the role of IR in PCOS independent of obesity remains unclear. This IR is greater in incidence and magnitude for obese subjects, but it is also found in non-obese subjects with PCOS (46). In a cross-sectional study, 46 of 143 women with PCOS (according to the NIH criteria) had glucose tolerance abnormalities, 16 had impaired fasting glucose (IFG) indicative of hepatic IR, ten had impaired glucose tolerance (IGT) indicative of peripheral IR, and 20 had combined glucose intolerance (CGI) indicative of combined hepatic and peripheral IR (47). Age was found to be a determinant of glucose intolerance while obesity was a determinant of IR. Despite these associations, this study also highlighted that even those with normal glucose tolerance may be severely insulin resistant and that the CVR factors of higher triglycerides and hs-CRP, with lower HDL levels, worsen before hyperglycemia. The authors proposed not only that IR increases with weight gain, but also that a decrease in overall insulin levels results in IFG, while a decrease in the early insulin response results in IGT/CGI even if the overall insulin levels are elevated. These subjects were not classified according to the Rotterdam criteria and further work needs to be undertaken to define whether the differing PCOS phenotypes are associated with IFG, IGT, or CGI. It has recently been shown that women with $\mathrm{NIH}$ and non-NIH PCOS have similar Finnish Diabetes Risk Scores and increased scores relative to controls independent of age and adiposity (48).

\section{Type 2 diabetes risk and PCOS}

Several relatively small studies have shown an increase in IGT and the development of type 2 diabetes amongst PCOS patients, particularly in subjects with a positive family history $(49,50,51,52,53,54)$. The AE-PCOS Society consensus statement (12) recommends a $2 \mathrm{~h}$ post-75 g oral glucose challenge to be performed in PCOS women with a BMI $>30 \mathrm{~kg} / \mathrm{m}^{2}$, or alternatively in lean PCOS women with advanced age ( $>40$ years), personal history of gestational diabetes, or family history of type 2 diabetes. They also suggest that patients with normal glucose tolerance be rescreened every 2 years or sooner if additional risk factors are identified (12). Risk factors for the development of 
diabetes are compounded by obesity (49). In the WISE study (2), women with the clinical features of PCOS were more likely to have diabetes, with a twofold higher incidence of diabetes reported in the Coronary Artery Risk Development in Young Adults Cohort, although the group with persistent PCOS consisted of only 11 women (55). However, this was not seen in the population of the Dallas cross-sectional study, though IR was demonstrated (31). Does this impact on CHD? While baseline diabetes is a strong predictor of $\mathrm{CHD}$ mortality when excluded from the multivariate analysis, menstrual irregularity continued to be a strong predictor of CHD mortality (5). In another cross-sectional study, 46 of 143 women with PCOS had glucose tolerance abnormalities, of whom 16 had IFG, ten had IGT, and 20 had CGI (47). In a recent metaanalysis, PCOS was associated with a 2.5-fold higher risk for IGT and a 4.5-fold higher risk for type 2 diabetes (56). It is recognized that patients with glucose abnormalities have a higher conversion to type 2 diabetes, and it has been suggested that an oral glucose tolerance test should be performed every 2 years for those with normal glucose tolerance and annually if IFG or IGT is present (2). This consensus statement also endorsed the use of an $\mathrm{HbA} 1 \mathrm{c}>6.5 \%$ as proposed for diabetes diagnosis (57). However, caution should be exercised as patients with type 2 diabetes may be missed (58), and the utilization of $\mathrm{HbAlc}$ for the diagnosis of diabetes in PCOS needs better definition.

\section{Dyslipidemia in PCOS}

Dyslipidemia is common in PCOS and is present in up to $70 \%$ of subjects $(2,59)$. An atherogenic lipid profile has been described that is not consistent between studies but may include high LDL and triglyceride levels, altered LDL quality, and a low HDL level consistent with increased CVR. The AE-PCOS Society consensus statement (12) recommends a complete lipid profile including LDL-cholesterol, non-HDL-cholesterol, HDL-cholesterol, and triglycerides in all patients with PCOS. The severity of the dyslipidemia appears to vary according to the phenotype with the most severe lipid abnormalities affecting the traditional PCOS, and much milder with other phenotypes such as the ovulatory variant (60). In a study comparing PCOS patients with weight-matched normal controls, there were no differences in LDL levels, but there were higher levels of smaller LDL size and higher concentrations of Lp(a), indicating a more atherogenic profile in one-third of patients (61). In a comparison between anovulatory and ovulatory PCOS patients, it was found that $\operatorname{Lp}(\mathrm{a})$ and small dense LDL were higher in the anovulatory subjects, and IR independently correlated with decreased HDL levels and elevated small dense LDL (60). The origin of the small dense LDL is likely to be from the elevated triglycerides via hepatic lipase that may reflect the presence of non-alcoholic fatty liver disease (NAFLD), as discussed below. In a recent metaanalysis, dyslipidemia was found to be common in women with PCOS. Beyond known alterations in triglycerides and HDL-cholesterol, women with PCOS have higher LDL-cholesterol and non-HDL-cholesterol, regardless of BMI, and it is recommended that all women with PCOS be screened for dyslipidemia, including LDL-cholesterol and non-HDL-cholesterol determinations, for effective CVR prevention (62).

The question then arises, is dyslipidemia a risk factor secondary to obesity or mainly a consequence of the PCOS state? Two studies have addressed this using statin therapy. In the first, atorvastatin was used in a double-blind placebo-controlled trial and was shown to reduce lipid parameters, IR, and hs-CRP and with a significant increase in sex hormone binding globulin (63). In a follow-up study, when those patients initially treated with atorvastatin were given subsequent metformin therapy, IR and the metabolic parameters of patients were maintained for a further 12-week period, though the cholesterol parameters increased on cessation of the statin (64). In a second study using simvastatin with and without metformin, lipid parameters, hs-CRP, and soluble adhesion molecule-1 decreased, and the combination with metformin afforded no additional benefit (65). While it is possible that the pleiotropic effects of statin therapy were responsible for these effects, the alternative hypothesis is that the reduction in cholesterol and improvement in the dyslipidemia were the primary mechanisms.

While these studies are promising, there is concern over the teratogenic effects of statins in women of childbearing age. Furthermore, we do not have the data to advise us on whether we should be addressing the dyslipidemia as either primary prevention or, as for diabetes, secondary prevention. The lipid levels in the literature suggest that treatment is arbitrary as no definitive studies have been performed in PCOS. Equally, treatment thresholds are difficult as these patients are young and even in the scenario of a subject with the combination of IGT, hypertension, and a high total cholesterol/HDL ratio, when put into traditional risk engines such as Framingham, or UKPDS, then such a patient will have a low CVD risk because of their youth.

\section{NAFLD in PCOS}

The prevalence of NAFLD may be as high as 55\% (66), though this may show ethnic differences with only $39 \%$ of Chinese subjects having been shown to have NAFLD (67). It is recognized that NAFLD is associated with IR and CVR, but it is not clear whether the coexistence of PCOS and NAFLD has an additive effect on CVR. In the study of Chinese subjects with PCOS and NAFLD using ultrasound, mesenteric thickness as a measure of visceral adiposity was related to NAFLD and IR (67). 
The question then arises, how do we address this NAFLD in PCOS? One way to address this was shown in a study with a double-blind, placebo-controlled (olive oil), crossover trial with marine omega- 3 fatty acids $(4 \mathrm{~g}$ daily) (66). Liver fat content measured by liver MRI decreased significantly, as did serum triglycerides and systolic and diastolic blood pressure, although there were no effects on BMI, non-esterified fatty acids, IR, hs-CRP, or androgen status. Metformin treatment for 6-12 months also improved hepatic parameters by reducing biochemical markers of NAFLD $(62,63)$. Further studies, perhaps using GLP-1 analogues or thiazolidinediones that have been used in NAFLD studies, need to be performed in patients with concomitant PCOS to determine the optimal treatment.

\section{Medical intervention in PCOS}

Lifestyle modification is recommended as the first-line therapy for the avoidance of CVR, but there are little data on its effectiveness (2). A study of exercise training in overweight and obese women with and without PCOS showed that visceral fat correlated with IR; after 12 weeks of intensive supervised exercise, both IR and visceral fat decreased significantly but there was no linear correlation. Although weight was unchanged, triglyceride levels fell (68). This study also highlights the difficulty in performing exercise trials in PCOS; of 117 women eligible following screening, only 34 agreed to participate and only 21 completed the study.

The question remains, can these markers of endothelial dysfunction be modified by treatment? Earlier studies on PCOS women have shown a beneficial effect of metformin on markers of endothelial dysfunction (18, $32,33)$. In a double-blind placebo-controlled trial with the insulin sensitizer metformin $500 \mathrm{mg}$ three times daily, arterial stiffness, blood pressure, pulse wave velocity, and endothelial function were improved over a 12 -week period (69). In a longer 6-month study comparing metformin $850 \mathrm{mg}$ twice daily with pioglitazone $30 \mathrm{mg}$ once daily, both insulin sensitizers returned endothelial function to normal (measured by FMD) in PCOS subjects; this correlated with the decrease in IR (70). However, patients were not hypertensive or dyslipidemic compared with controls, and it is recognized that these parameters have an independent effect on endothelial cell function that may abrogate treatment effects and account for the discrepancies in other studies.

Many patients with PCOS are treated with oral contraceptive agents for their menstrual irregularity and hirsutism. Drospirenone (DRSP) is a $17 \alpha$-spironolactone derivative progestin that combines progestogenic activity with anti-androgenic and anti-mineralocorticoid activity that may therefore have a beneficial CVR profile $(71,72,73)$. In one study on 16 lean and 12 overweight PCOS subjects, after giving $30 \mu \mathrm{g}$ ethinyl estradiol $\left(\mathrm{E}_{2}\right)$ and $3 \mathrm{mg}$ DRSP for 6 months, no effects were found on endothelial function or CVR indices (71). In a second study, ethinyl $\mathrm{E}_{2} /$ DRSP was associated with an increase in systolic, diastolic and 24-h blood pressure of about $5 \mathrm{mmHg}$ and an increase in triglyceride levels (72). A third study using a lower dose of $20 \mu \mathrm{g}$ ethinyl $\mathrm{E}_{2}$ showed improved insulin sensitivity and did not adversely affect blood pressure or serum lipid values, effects that were not enhanced with the addition of metformin (73). The optimal estrogen containing oral contraceptive for PCOS needs clarification, but these studies suggest that the combination of $20 \mu \mathrm{g}$ ethinyl $\mathrm{E}_{2}$ with $3 \mathrm{mg}$ DRSP may at least be neutral on CVR. In a meta-analysis to investigate the association between oral contraceptive use and dysglycemia, dyslipidemia, and IR in women with PCOS, it was found that use of oral contraceptives was not associated with clinically significant adverse metabolic consequences (74). However, due to limitations of the underlying studies, further research including rigorously designed randomized trials is needed.

Recent data demonstrate a potent effect of DRSP in inhibiting adipogenesis through its specific anti-mineralocorticoid properties. Thereby, DRSP may display favorable metabolic effects in women, in adequate combination with estrogens, to prevent excessive adipose tissue deposition and its related cardiometabolic complications (75).

In summary, further larger studies on lifestyle intervention and the combination of insulin sensitization with oral contraceptive use are needed to help define optimal medical therapy in PCOS.

\section{Summary}

Hercules overcame the Hydra by cauterizing the wound after cutting off each head to prevent more heads from appearing. It is clear that without definitive prospective studies, the natural history of CVD and diabetes development will not be defined clearly enough to allow appropriate risk strategies to be implemented. Uncertainty over CVD will continue to prevail, and the increased publication of surrogate markers of CVD will continue unabated. Should increased CVD risk be proven, there will be a need for long-term prospective studies to address whether we can modify those factors for CVD. From this review, there is evidence that visceral obesity may exacerbate the PCOS phenotype and endothelial dysfunction data add to the existing body of evidence suggesting that these patients are at risk of accelerated atherosclerosis. It is still not clear why we do not see an overwhelming increase in morbidity and mortality in view of the wealth of CVR factors. Is it due to the protective youth of these patients, or is it restricted to those that subsequently develop diabetes and the added metabolic burden of that condition? 


\section{Declaration of interest}

T Sathyapalan and S L Atkin do not have any conflicts of interest to declare with respect to this manuscript.

\section{Funding}

T Sathyapalan and S L Atkin are employees of University of Hull. No funding was involved in preparation of this manuscript.

\section{References}

1 Rotterdam ESHRE/ASRM-Sponsored PCOS Consensus Workshop Group. Revised 2003 consensus on diagnostic criteria and longterm health risks related to polycystic ovary syndrome (PCOS). Human Reproduction 200419 41-47. (doi:10.1093/humrep/ deh098)

2 Wild RA, Carmina E, Diamanti KE, Dokras A, Escobar MHF, Futterweit W, Lobo R, Norman RJ, Talbott E \& Dumesic DA. Assessment of cardiovascular risk and prevention of cardiovascular disease in women with the polycystic ovary syndrome: a consensus statement by the Androgen Excess and Polycystic Ovary Syndrome (AE-PCOS) Society. Journal of Clinical Endocrinology and Metabolism 201095 2038-2049. (doi:10.1210/jc.2009-2724)

3 Azziz R, Carmina E, Dewailly D, Diamanti-Kandarakis E, EscobarMorreale HF, Futterweit W, Janssen OE, Legro RS, Norman RJ, Taylor AE \& Witchel SF. The Androgen Excess and PCOS Society criteria for the polycystic ovary syndrome: the complete task force report. Fertility and Sterility 200991 456-488. (doi:10.1016/j. fertnstert.2008.06.035)

4 Solomon CG, Hu FB, Dunaif A, Rich-Edwards JE, Stampfer MJ, Willett WC, Speizer FE \& Manson JE. Menstrual cycle irregularity and risk for future cardiovascular disease. Journal of Clinical Endocrinology and Metabolism 200287 2013-2017. (doi:10. 1210/jc.87.5.2013)

5 Wang ET, Cirillo PM, Vittinghoff E, Bibbins-Domingo K, Cohn BA \& Cedars MI. Menstrual irregularity and cardiovascular mortality. Journal of Clinical Endocrinology and Metabolism 201196 E114-E118. (doi:10.1210/jc.2010-1709)

6 Laughlin GA, Goodell V \& Barrett-Connor E. Extremes of endogenous testosterone are associated with increased risk of incident coronary events in older women. Journal of Clinical Endocrinology and Metabolism 201095 740-747. (doi:10.1210/jc. 2009-1693)

7 Patel SM, Ratcliffe SJ, Reilly MP, Weinstein R, Bhasin S, Blackman MR, Cauley JA, Sutton-Tyrrell K, Robbins J, Fried LP \& Cappola AR. Higher serum testosterone concentration in older women is associated with insulin resistance, metabolic syndrome, and cardiovascular disease. Journal of Clinical Endocrinology and Metabolism 2009 94 4776-4784. (doi:10.1210/jc.2009-0740)

8 Puurunen J, Piltonen T, Morin-Papunen L, Perheentupa A, Jarvela I, Ruokonen A \& Tapanainen JS. Unfavorable hormonal, metabolic, and inflammatory alterations persist after menopause in women with PCOS. Journal of Clinical Endocrinology and Metabolism 2011 96 1827-1834. (doi:10.1210/jc.2011-0039)

9 Jovanovic VP, Carmina E \& Lobo RA. Not all women diagnosed with PCOS share the same cardiovascular risk profiles. Fertility and Sterility 201094 826-832. (doi:10.1016/j.fertnstert.2009. 04.021)

10 Wiltgen D \& Spritzer PM. Variation in metabolic and cardiovascular risk in women with different polycystic ovary syndrome phenotypes. Fertility and Sterility 201094 2493-2496. (doi:10. 1016/j.fertnstert.2010.02.015)

11 Zhang HY, Zhu FF, Xiong J, Shi XB \& Fu SX. Characteristics of different phenotypes of polycystic ovary syndrome based on the Rotterdam criteria in a large-scale Chinese population. BJOG: an International Journal of Obstetrics and Gynaecology 2009116 1633-1639. (doi:10.1111/j.1471-0528.2009.02347.x)
12 Wild RA, Carmina E, Diamanti-Kandarakis E, Dokras A, EscobarMorreale HF, Futterweit W, Lobo R, Norman RJ, Talbott E \& Dumesic DA. Assessment of cardiovascular risk and prevention of cardiovascular disease in women with the polycystic ovary syndrome: a consensus statement by the Androgen Excess and Polycystic Ovary Syndrome (AE-PCOS) Society. Journal of Clinical Endocrinology and Metabolism 201095 2038-2049. (doi:10. 1210/jc.2009-2724)

13 de Groot PC, Dekkers OM, Romijn JA, Dieben SW \& Helmerhorst FM. PCOS, coronary heart disease, stroke and the influence of obesity: a systematic review and meta-analysis. Human Reproduction Update 201117 495-500. (doi:10.1093/ humupd/dmrOO1)

14 Diamanti-Kandarakis E \& Panidis D. Unravelling the phenotypic map of polycystic ovary syndrome (PCOS): a prospective study of 634 women with PCOS. Clinical Endocrinology 200767 735-742. (doi:10.1111/j.1365-2265.2007.02954.x)

15 Toulis KA, Goulis DG, Mintziori G, Kintiraki E, Eukarpidis E, Mouratoglou SA, Pavlaki A, Stergianos S, Poulasouchidou M, Tzellos TG, Makedos A, Chourdakis M \& Tarlatzis BC. Metaanalysis of cardiovascular disease risk markers in women with polycystic ovary syndrome. Human Reproduction Update 201117 741-760. (doi:10.1093/humupd/dmr025)

16 Diamanti-Kandarakis E, Katsikis I, Piperi C, Kandaraki E, Piouka A, Papavassiliou AG \& Panidis D. Increased serum advanced glycation end-products is a distinct finding in lean women with polycystic ovary syndrome (PCOS). Clinical Endocrinology 200869 634-641. (doi:10.1111/j.1365-2265. 2008.03247.x)

17 Diamanti-Kandarakis E, Lambrinoudaki I, Economou F, Christou M, Piperi C, Papavassiliou AG \& Creatsas G. Androgens associated with advanced glycation end-products in postmenopausal women. Menopause 201017 1182-1187. (doi:10.1097/ gme.0b013e3181e170af)

18 Diamanti-Kandarakis E, Spina G, Kouli C \& Migdalis I. Increased endothelin-1 levels in women with polycystic ovary syndrome and the beneficial effect of metformin therapy. Journal of Clinical Endocrinology and Metabolism 200186 4666-4673. (doi:10. 1210/jc.86.10.4666)

19 Kaya C, Pabuccu R, Berker B \& Satiroglu H. Plasma interleukin-18 levels are increased in the polycystic ovary syndrome: relationship of carotid intima-media wall thickness and cardiovascular risk factors. Fertility and Sterility 201093 1200-1207. (doi:10.1016/ j.fertnstert.2008.10.070)

20 Kaya C, Erkan AF, Cengiz SD, Dünder I, Demirel OE \& Bilgihan A. Advanced oxidation protein products are increased in women with polycystic ovary syndrome: relationship with traditional and nontraditional cardiovascular risk factors in patients with polycystic ovary syndrome. Fertility and Sterility $2009921372-$ 1377. (doi:10.1016/j.fertnstert.2008.08.016)

21 Caglar GS, Oztas E, Karadag D, Pabuccu R \& Demirtas S. Ischemiamodified albumin and cardiovascular risk markers in polycystic ovary syndrome with or without insulin resistance. Fertility and Sterility 201195 310-313. (doi:10.1016/j.fertnstert.2010. 06.092)

22 Duleba AJ \& Ahmed IM. Predictors of urinary albumin excretion in women with polycystic ovary syndrome. Fertility and Sterility 201093 2285-2290. (doi:10.1016/j.fertnstert.2008.12.120)

23 Moran LJ, Cameron JD, Strauss BJ \& Teede HJ. Vascular function in the diagnostic categories of polycystic ovary syndrome. Human Reproduction 201126 2192-2199. (doi:10.1093/ humrep/der159)

24 Dereli D, Ozgen G, Buyukkececi F, Guney E \& Yilmaz C. Platelet dysfunction in lean women with polycystic ovary syndrome and association with insulin sensitivity. Journal of Clinical Endocrinology and Metabolism $2003 \mathbf{8 8}$ 2263-2268. (doi:10.1210/jc.2002021391)

25 Rajendran S, Willoughby SR, Chan WPA, Liberts EA, Heresztyn T, Saha M, Marber MS, Norman RJ \& Horowitz JD. Polycystic ovary syndrome is associated with severe platelet and endothelial 
dysfunction in both obese and lean subjects. Atherosclerosis 2009 204 509-514. (doi:10.1016/j.atherosclerosis.2008.09.010)

26 Wiltgen D, Benedetto IG, Mastella LS \& Spritzer PM. Lipid accumulation product index: a reliable marker of cardiovascular risk in polycystic ovary syndrome. Human Reproduction $2009 \mathbf{2 4}$ 1726-1731. (doi:10.1093/humrep/dep072)

27 Mather KJ. Verma S, Corenblum B \& Anderson TJ. Normal endothelial function despite insulin resistance in healthy women with the polycystic ovary syndrome. Journal of Clinical Endocrinology and Metabolism 200085 1851-1856. (doi:10.1210/jc.85.5.1851)

28 Paradisi G, Steinberg HO, Hempfling A, Cronin J, Hook G, Shepard MK \& Baron AD. Polycystic ovary syndrome is associated with endothelial dysfunction. Circulation 2001103 1410-1415. (doi:10.1161/01.CIR.103.10.1410)

29 Orio F Jr, Palomba S, Cascella T, De Simone B, Di Biase S, Russo T, Labella D, Zullo F, Lombardi G \& Colao A. Early impairment of endothelial structure and function in young normal-weight women with polycystic ovary syndrome. Journal of Clinical Endocrinology and Metabolism 200489 4588-4593. (doi:10. 1210/jc.2003-031867)

30 Tarkun I, Arslan BC, Canturk Z, Turemen E, Sahin T \& Duman C. Endothelial dysfunction in young women with polycystic ovary syndrome: relationship with insulin resistance and low-grade chronic inflammation. Journal of Clinical Endocrinology and Metabolism 200489 5592-5596. (doi:10.1210/jc.2004-0751)

31 Chang AY, Ayers C, Minhajuddin A, Jain T, Nurenberg P, de Limos JA, Wild RA \& Auchus RJ. Polycystic ovarian syndrome and subclinical atherosclerosis among women of reproductive age in the Dallas heart study. Clinical Endocrinology 2011 74 89-96. (doi:10.1111/j.1365-2265.2010.03907.x)

32 Diamanti-Kandarakis E, Alexandraki K, Protogerou A, Piperi C, Papamichael C, Aessopos A, Lekakis J \& Mavrikakis M. Metformin administration improves endothelial function in women with polycystic ovary syndrome. European Journal of Endocrinology 2005 152 749-756. (doi:10.1530/eje.1.01910)

33 Sorensen MB, Franks S, Robertson C, Pennell DJ \& Collins P. Severe endothelial dysfunction in young women with polycystic ovary syndrome is only partially explained by known cardiovascular risk factors. Clinical Endocrinology 200665 655-659. (doi:10.1111/j. 1365-2265.2006.02645.x)

34 Mancini F, Cianciosi A, Reggiani GM, Facchinetti F, Battaglia C \& de Aloysio D. Endothelial function and its relationship to leptin, homocysteine, and insulin resistance in lean and overweight eumenorrheic women and PCOS patients: a pilot study. Fertility and Sterility 200991 2537-2544. (doi:10.1016/j.fertnstert. 2008.03.023)

35 Battaglia C, Mancini F, Cianciosi A, Busacchi P, Persico N, Paradisi R, Facchinetti F \& de Aloysio D. Cardiovascular risk in normal weight, eumenorrheic, nonhirsute daughters of patients with polycystic ovary syndrome: a pilot study. Fertility and Sterility 200992 240-249. (doi:10.1016/j.fertnstert.2008.05.018)

36 Kaya MG, Gunebakmaz O, Zencir C, Yilmazsoy A, Karadag M, Topsakal R, Ergin A \& Kelestimur F. An assessment of the elastic properties of the aorta in nonobese women with polycystic ovary syndrome. Fertility and Sterility 201094 2402-2405. (doi:10. 1016/j.fertnstert.2010.04.002)

37 Ketel IJ, Stehouwer CD, Henry RM, Serné EH, Hompes P, Homburg R, Smulders YM \& Lambalk CB. Greater arterial stiffness in polycystic ovary syndrome PCOS is an obesity - but not a PCOSassociated phenomenon. Journal of Clinical Endocrinology and Metabolism 201095 4566-4575. (doi:10.1210/jc.2010-0868)

38 Cussons AJ, Watts GF \& Stuckey BG. Dissociation of endothelial function and arterial stiffness in nonobese women with polycystic ovary syndrome (PCOS). Clinical Endocrinology 200971 808-814. (doi:10.1111/j.1365-2265.2009.03598.x)

39 Yildirir A, Aybar F, Kabakci G, Yarali H \& Oto A. Heart rate variability in young women with polycystic ovary syndrome. Annals of Noninvasive Electrocardiology 200611 306-312. (doi:10. $1111 / \mathrm{j} .1542-474 \mathrm{X} .2006 .00122 . \mathrm{x})$

40 Giallauria F, Orio F, Lombardi G, Colao A, Vigorito C, Tafuri MG \& Palomba S. Relationship between heart rate recovery and inflammatory markers in patients with polycystic ovary syndrome: a cross-sectional study. Journal of Ovarian Research 20092 3. (doi:10.1186/1757-2215-2-3)

41 Fogel RB, Malhotra A, Pillar G, Pittman SD, Dunaif A \& White DP. Increased prevalence of obstructive sleep apnea syndrome in obese women with polycystic ovary syndrome. Journal of Clinical Endocrinology and Metabolism 200186 1175-1180. (doi:10. $1210 /$ jc.86.3.1175)

42 Tasali E, Chapotot F, Leproult R, Whitmore H \& Ehrmann DA. Treatment of obstructive sleep apnea improves cardiometabolic function in young obese women with polycystic ovary syndrome. Journal of Clinical Endocrinology and Metabolism 201196 365-374. (doi:10.1210/jc.2010-1187)

43 Wijeyaratne CN, Seneviratne Rde A, Dahanayake S, Kumarapeli V, Palipane E, Kuruppu N, Yapa C \& Balen AH. Phenotype and metabolic profile of South Asian women with polycystic ovary syndrome (PCOS): results of a large database from a specialist Endocrine Clinic. Human Reproduction 201126 202-213. (doi:10. 1093/humrep/deq310)

44 Carmina E \& Lobo RA. Use of fasting blood to assess the prevalence of insulin resistance in women with polycystic ovary syndrome. Fertility and Sterility 200482 661-665. (doi:10.1016/j.fertnstert. 2004.01.041)

45 DeUgarte CM, Bartolucci AA \& Azziz R. Prevalence of insulin resistance in the polycystic ovary syndrome using the homeostasis model assessment. Fertility and Sterility 200583 1454-1460. (doi:10.1016/j.fertnstert.2004.11.070)

46 Meirow D, Yossepowitch O, Rosler A, Brzezinski A, Schenker JG, Laufer N \& Raz I. Insulin resistant and non-resistant polycystic ovary syndrome represent two clinical and endocrinological subgroups. Human Reproduction 199510 1951-1956.

47 Karakas SE, Kim K \& Duleba AJ. Determinants of impaired fasting glucose versus glucose intolerance in polycystic ovary syndrome. Diabetes Care 201033 887-893. (doi:10.2337/dc09-1525)

48 Moran LJ, Strauss BJ \& Teede HJ. Diabetes risk score in the diagnostic categories of polycystic ovary syndrome. Fertility and Sterility 201195 1742-1748. (doi:10.1016/j.fertnstert.2011. 01.133)

49 Ehrmann DA, Barnes RB, Rosenfield RL, Cavaghan MK \& Imperial J. Prevalence of impaired glucose tolerance and diabetes in women with polycystic ovary syndrome. Diabetes Care 199922 141-146. (doi:10.2337/diacare.22.1.141)

50 Boudreaux MY, Talbott EO, Kip KE, Brooks MM \& Witchel SF. Risk of T2DM and impaired fasting glucose among PCOS subjects: results of an 8-year follow-up. Current Diabetes Reports 20066 77-83. (doi:10.1007/s11892-006-0056-1)

51 Talbott EO, Zborowski JV, Rager JR, Kip KE, Xu X \& Orchard TJ. Polycystic ovarian syndrome (PCOS): a significant contributor to the overall burden of type 2 diabetes in women. Journal of Women's Health 200716 191-197. (doi:10.1089/jwh.2006.0098)

52 Norman RJ, Masters L, Milner CR, Wang JX \& Davies MJ. Relative risk of conversion from normoglycaemia to impaired glucose tolerance or non-insulin dependent diabetes mellitus in polycystic ovarian syndrome. Human Reproduction 200116 1995-1998. (doi:10.1093/humrep/16.9.1995)

53 Magliano DJ, Barr EL, Zimmet PZ, Cameron AJ, Dunstan DW, Colagiuri S, Jolley D, Owen N, Phillips P, Tapp RJ, Welborn TA \& Shaw JE. Glucose indices, health behaviors, and incidence of diabetes in Australia: the Australian Diabetes, Obesity and Lifestyle Study. Diabetes Care 200831 267-272. (doi:10.2337/dc070912)

54 Ehrmann DA, Liljenquist DR, Kasza K, Azziz R, Legro RS \& Ghazzi MN. Prevalence and predictors of the metabolic syndrome in women with polycystic ovary syndrome. Journal of Clinical Endocrinology and Metabolism 200691 48-53. (doi:10.1210/jc. 2005-1329)

55 Wang ET, Calderon MR, Cedars MI, Daviglus ML, Merkin SS, Schreiner PJ, Sternfeld B, Wellons M, Schwartz SM, Lewis CE, Williams OD, Siscovick DS \& Bibbins DK. Polycystic ovary 
syndrome and risk for long-term diabetes and dyslipidemia. Obstetrics and Gynecology $2011 \mathbf{1 1 7}$ 6-13. (doi:10.1097/AOG. Ob013e31820209bb)

56 Moran LJ, Misso ML, Wild RA \& Norman RJ. Impaired glucose tolerance, type 2 diabetes and metabolic syndrome in polycystic ovary syndrome: a systematic review and meta-analysis. Human Reproduction Update 201016 347-363. (doi:10.1093/humupd/ dmq001)

57 American Diabetes Association. Diagnosis and classification of diabetes mellitus. Diabetes Care 201033 (Suppl 1) S62-S69. (doi:10.2337/dc10-S062)

58 Lorenzo C, Wagenknecht LE, Hanley AJ, Rewers MJ, Karter AJ \& Haffner SM. HbA1C between 5.7 and $6.4 \%$ as a marker for identifying pre-diabetes, insulin sensitivity and secretion, and cardiovascular risk factors: the Insulin Resistance Atherosclerosis Study (IRAS). Diabetes Care 201033 2104-2109. (doi:10.2337/ dc10-0679)

59 Rizzo M, Longo RA, Guastella E, Rini GB \& Carmina E. Assessing cardiovascular risk in mediterranean women with polycystic ovary syndrome. Journal of Endocrinological Investigation 201134 $422-426$.

60 Rizzo M, Berneis K, Hersberger M, Pepe I, Di Fede G, Rini GB, Spinas GA \& Carmina E. Milder forms of atherogenic dyslipidemia in ovulatory versus anovulatory polycystic ovary syndrome phenotype. Human Reproduction 200924 2286-2292. (doi:10. 1093/humrep/dep121)

61 Berneis K, Rizzo M, Hersberger M, Rini GB, Di Fede G, Pepe I, Spinas GA \& Carmina E. Atherogenic forms of dyslipidaemia in women with polycystic ovary syndrome. International Journal of Clinical Practice 200963 56-62. (doi:10.1111/j.1742-1241. 2008.01897.x)

62 Wild RA, Rizzo M, Clifton S \& Carmina E. Lipid levels in polycystic ovary syndrome: systematic review and meta-analysis. Fertility and Sterility 201195 1073-1079. (doi:10.1016/j.fertnstert. 2010.12.027)

63 Sathyapalan T, Kilpatrick ES, Coady AM \& Atkin SL. The effect of atorvastatin in patients with polycystic ovary syndrome: a randomized double-blind placebo-controlled study. Journal of Clinical Endocrinology and Metabolism 2009 94 103-108. (doi:10.1210/jc.2008-1750)

64 Sathyapalan T, Kilpatrick ES, Coady AM \& Atkin SL. Atorvastatin pretreatment augments the effect of metformin in patients with polycystic ovary syndrome (PCOS). Clinical Endocrinology 201072 566-568. (doi:10.1111/j.1365-2265.2009.03678.x)

65 Banaszewska B, Spaczynski R \& Pawelczyk L. Statins in the treatment of polycystic ovary syndrome. Ginekologia Polska 2010 81 618-621.

66 Cussons AJ, Watts GF, Mori TA \& Stuckey BGA. Omega-3 fatty acid supplementation decreases liver fat content in polycystic ovary syndrome: a randomized controlled trial employing proton magnetic resonance spectroscopy. Journal of Clinical Endocrinology and Metabolism 200994 3842-3848. (doi:10.1210/jc.20090870)

67 Ma RCW, Liu KH, Lam PM, Cheung LP, Tam WH, Ko GTC, Chan MHM, Ho CS, Lam CWK, Chu WCW, Tong PCY, So WY, Chan JCN \& Chow CC. Sonographic measurement of mesenteric fat predicts presence of fatty liver among subjects with polycystic ovary syndrome. Journal of Clinical Endocrinology and Metabolism 201196 799-807. (doi:10.1210/jc.2010-1608)

68 Hutchison SK, Stepto NK, Harrison CL, Moran LJ, Strauss BJ \& Teede HJ. Effects of exercise on insulin resistance and body composition in overweight and obese women with and without polycystic ovary syndrome. Journal of Clinical Endocrinology and Metabolism 201196 E48-E56. (doi:10.1210/jc.2010-0828)

69 Agarwal N, Rice SPL, Bolusani H, Luzio SD, Dunseath G, Ludgate M \& Rees DA. Metformin reduces arterial stiffness and improves endothelial function in young women with polycystic ovary syndrome: a randomized, placebo-controlled, crossover trial. Journal of Clinical Endocrinology and Metabolism 201095 722-730. (doi:10.1210/jc.2009-1985)

70 Naka KK, Kalantaridou SN, Kravariti M, Bechlioulis A, Kazakos N, Calis KA, Makrigiannakis A, Katsouras CS, Chrousos GP, Tsatsoulis A \& Michalis LK. Effect of the insulin sensitizers metformin and pioglitazone on endothelial function in young women with polycystic ovary syndrome: a prospective randomized study. Fertility and Sterility 201195 203-209. (doi:10.1016/j. fertnstert.2010.06.058)

71 Mancini F, Cianciosi A, Persico N, Facchinetti F, Busacchi P \& Battaglia C. Drospirenone and cardiovascular risk in lean and obese polycystic ovary syndrome patients: a pilot study. American Journal of Obstetrics and Gynecology 2010202 169.e1-169.e8. (doi:10.1016/j.ajog.2009.09.038)

72 Battaglia C, Mancini F, Fabbri R, Persico N, Busacchi P, Facchinetti F \& Venturoli S. Polycystic ovary syndrome and cardiovascular risk in young patients treated with drospirenoneethinylestradiol or contraceptive vaginal ring A prospective, randomized, pilot study. Fertility and Sterility $2010 \mathbf{9 4}$ 1417-1425. (doi:10.1016/j.fertnstert.2009.05.044)

73 Fruzzetti F, Perini D, Lazzarini V, Parrini D, Gambacciani M \& Genazzani AR. Comparison of effects of $3 \mathrm{mg}$ drospirenone plus $20 \mu \mathrm{g}$ ethinyl estradiol alone or combined with metformin or cyproterone acetate on classic metabolic cardiovascular risk factors in nonobese women with polycystic ovary syndrome. Fertility and Sterility 201094 1793-1798. (doi:10.1016/j. fertnstert.2009.10.016)

74 Halperin IJ. Kumar SS, Stroup DF \& Laredo SE. The association between the combined oral contraceptive pill and insulin resistance, dysglycemia and dyslipidemia in women with polycystic ovary syndrome: a systematic review and meta-analysis of observational studies. Human Reproduction 201126 191-201. (doi:10.1093/humrep/deq301)

75 Caprio M, Antelmi A, Chetrite G, Muscat A, Mammi C, Marzolla V, Fabbri A, Zennaro MC \& Feve B. Antiadipogenic effects of the mineralocorticoid receptor antagonist drospirenone: potential implications for the treatment of metabolic syndrome. Endocrinology 2011152 113-125. (doi:10.1210/en.2010-0674)

Received 26 August 2011

Revised version received 15 November 2011

Accepted 17 November 2011 